\title{
Morphological changes in the human conjunctival epithelium. I. In the normal elderly population
}

\author{
L. M. R. ABDEL-KHALEK, ${ }^{1}$ J. WILLIAMSON, ${ }^{2}$ AND W. R. LEE ${ }^{1}$ \\ From the Departments of Ophthalmology and Pathology, ${ }^{1}$ University of Glasgow, and the ${ }^{2}$ Southern General \\ Hospital, Glasgow
}

SUMMARY Forty-nine biopsies of bulbar conjunctiva from patients with no apparent conjunctival disease were studied by light and transmission electron microscopy. No significant morphological changes were recorded in those specimens from patients less than 79 years old. However, in the older age group the epithelium showed irregularities in thickness, a reduction in the goblet cell population, and in $25 \%$ the presence of 'hyaline bodies'. The epithelial irregularities consisted of mild superficial stratification, which was observed also in a few of the specimens from the younger age groups. The goblet cells appeared morphologically normal in all age groups. The significance of the hyaline bodies and their possible relationship to goblet cells is discussed.

Clinical studies have shown that tear secretion decreases in quantity and quality in the later decade of life, and mild keratoconjunctivitis sicca (KCS) can be identified in approximately $15 \%$ of people over the age of 80 years (Whaley et al., 1972). Accordingly, it is possible that there are significant morphological changes in the conjunctival epithelium of the elderly, and it is important that these changes be documented to provide the necessary background information for the study of the conjunctiva in KCS (part II of this communication). This part of the report describes the light and electron microscope findings in the conjunctiva of a group of elderly persons.

\section{Materials and methods}

Forty-nine conjunctival biopsies from patients without apparent conjunctival disease were obtained during the course of routine cataract surgery. The operations were performed using retrobulbar injection of $1.5 \mathrm{ml}$ lignocaine and with local instillation of $0.4 \%$ oxybuprocaine $\mathrm{HCl}$ drops. The details of the sex and age distribution of the group are shown in Table 1.

The biopsies, which were approximately $5 \mathrm{~mm}$ in diameter, were removed from the upper bulbar conjunctiva at a consistent site which was $5 \mathrm{~mm}$

Address for reprints: $\mathrm{Dr}$ W. R. Lee, Department of Ophthalmology, University of Glasgow, Western Infirmary, Glasgow G11 6NT
Table 1 Distribution of patients according to age and sex

\begin{tabular}{llcc}
\hline Age (years) & Male & Female & Total* \\
\hline $50-59$ & 1 & 3 & $4(3)$ \\
$60-69$ & 3 & 7 & $10(5)$ \\
$70-79$ & 5 & 14 & $19(8)$ \\
$80-89$ & 3 & 13 & $16(9)$ \\
Total & 12 & 37 & $49(25)$
\end{tabular}

*The figures in parentheses indicate the number of biopsies studies by electron microscopy

from the limbus. Some of the biopsies were laid out on filter paper before fixation, but the majority were immersed immediately in $4 \%$ phosphate buffered glutaraldehyde. The latter technique was found to be preferable because stretching of the tissues on to the filter paper introduced artefactual damage to the epithelium.

Each specimen was then divided: half was processed for light microscopy, the other half for conventional transmission electron microscopy.

\section{LIGHT MICROSCOPY}

Qualitative assessment. The sections which were prepared from paraffin-embedded blocks were stained with haematoxylin and eosin, PAS, and orcein stains and were coded and assessed with regard to the following features: (1) Changes in the arrangement of the epithelial cells; (2) changes in 
Fig. 1 Light micrograph to show 'hyaline bodies' (large arrows) in a segment of epithelium which also contains goblet cells (small arrows). $H$. and $E$., $\times 385$

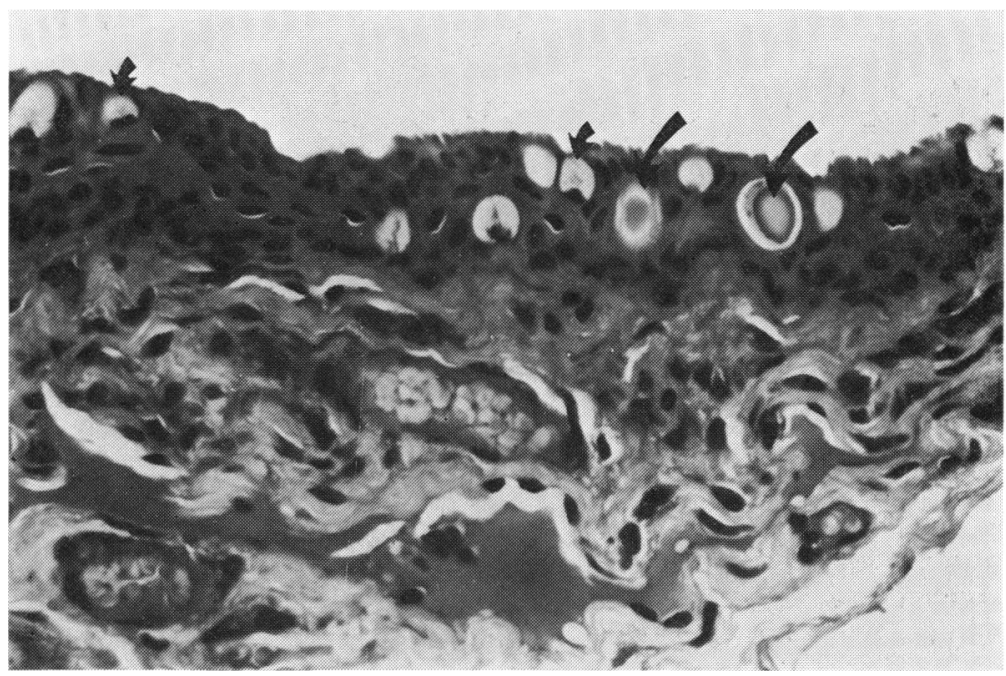

the morphology and arrangement of goblet cells; (3) changes in the inflammatory cell content of the conjunctival stroma.

Quantitative assessment of goblet cell. A count of epithelial goblet cells was performed on PASstained sections by means of a calibrated eyepiece graticule and a $\times 10$ objective in a Leitz HM LUX light microscope. The number of goblet cells was expressed as the frequency per $\mathrm{mm}$ length of epithelium.

\section{TRANSMISSION ELECTRON MICROSCOPY}

The glutaraldehyde-fixed specimens were postfixed in $2 \%$ phosphate buffered osmium-tetroxide, passed through ascending grades of alcohol, and finally embedded in Araldite. Semithin $(1 \mu)$ and ultrathin $(500 \AA[50 \mathrm{~nm}])$ sections were then cut on an LKB Ultrotome III. The semithin sections were stained with toluidine blue and were used for orientation. The ultrathin sections were double stained with uranyl acetate and lead citrate and were examined in the Phillips 301 EM.

\section{Results}

\section{LIGHT MICROSCOPY}

\section{Qualitative assessment}

The specimens were examined without prior knowledge of the age and sex of the patients. Significant alterations were found only in the epithelium of those over 80 years, so that the results can be presented in two parts.

(1) Persons under 80 years. The conjunctival epithelial morphology was identical with the estab- lished descriptions in the literature (Wolfe, 1967). There were no significant changes in the epithelial thickness or in the arrangement of the cells. The normal human bulbar conjunctiva in the region examined consisted of a 5- or more polyhedral nonkeratinised epithelium with a basal cubical layer which lay above a folded basement membrane. Goblet cells were usually present in the superficial layers, and they tended to occur in aggregates, so that some epithelial segments contained more goblet cells than others.

(2) Persons over 80 years. The following features were of significance: ( $i)$ Variation in the epithelial thickness. This was seen as mild atrophy in some biopsies and an apparent but mild degree of hyperplasia in others. However, in all the specimens examined these irregularities tended to be focal, and long segments of epithelium of normal thickness alternated with the atrophic or hyperplastic areas. (ii) Abnormal structures in the epithelium; "hyaline bodies'. In 4 of the 16 biopsies taken from persons ( 2 male and 2 female) over 80 years old, round or ovoid acellular structures were identified (Fig. 1). These were present in the superficial layers and were much larger than the adjacent goblet cells. They stained positively with the PAS stain and their content, unlike that of the goblet cells, was homogeneous. For convenience they were classified as being of a hyaline nature. (iii) Inflammatory cells, lymphocytes, plasma cells, and polymorphonuclear leucocytes were identified in the stroma and in the epithelium in this group of biopsies, but in distribution and number there was no significant pattern and no difference could be detected between the over- and the under-80s. 

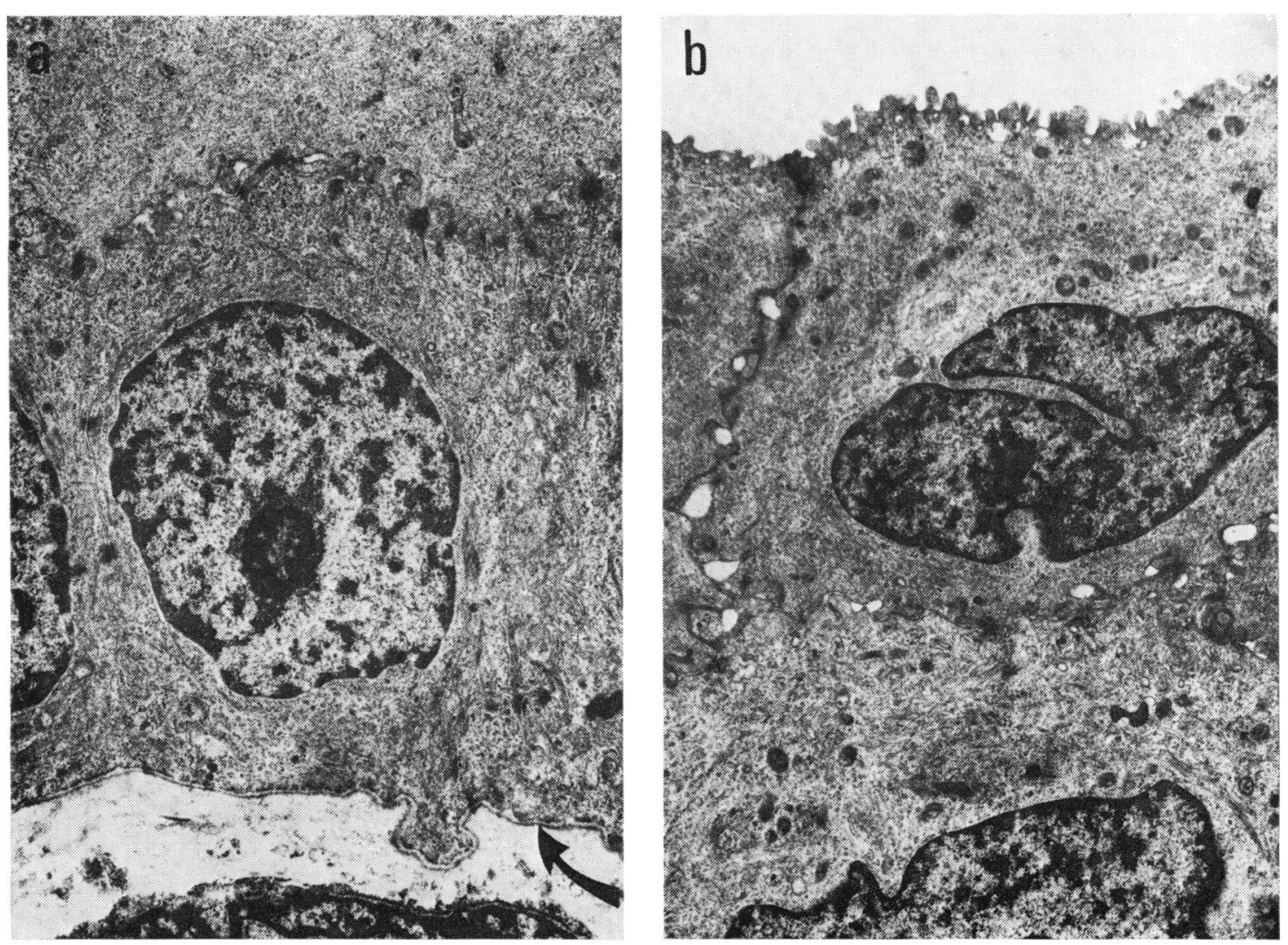

Fig. 2 (a) The cubical basal cell layer in a 62-year-old patient's conjunctival epithelium. The basement membrane is shown by an arrow $(\times 6800)$. (b) The polygonal superficial cells in the conjunctival epithelium of the same individual. Note the wide intercellular spaces between the cells in this layer $(\times 6800)$

\section{Quantitative assessment}

The results obtained in the goblet cell count are shown in Table 2. In the group aged 50 to 79 the mean value $( \pm S D)$ was $10 \pm 4$ goblet cells $/ \mathrm{mm}$, with no significant statistical difference in the 3 age groups shown. However, in the group over 80 years the mean goblet cell count $( \pm S D)$ was $16 \pm 3$ goblet cells $/ \mathrm{mm}$, and this is significantly lower than that in younger age groups $(P<0.05)$. The observer error in this analysis was less than $5 \%$.

Table 2 Goblet cell count in the conjunctival epithelium according to age

\begin{tabular}{lll}
\hline Age (years) & Number of biopsies & Goblet cell/mm $\pm S D$ \\
\hline $50-59$ & 4 & $10 \cdot 2 \pm 3 \cdot 5$ \\
$60-69$ & 10 & $10 \cdot 2 \pm 4$ \\
$70-79$ & 19 & $9 \cdot 4 \pm 3 \cdot 8$ \\
$80-89$ & 16 & $6 \cdot 4 \pm 3$ \\
\hline
\end{tabular}

ELECTRON MICROSCOPY

Twenty-five biopsies were studied by transmission electron microscopy (Table 1). The morphology of the palpebral conjunctival epithelium has been described by Wanko et al. (1964), so that it is only necessary to outline the basic structure of the 3 cell layers and to emphasise the changes in structure which may be related to the ageing process. The essential morphological features of the epithelium were as follows.

\section{Basal cells}

The basal cell layer consisted of cubical cells which had a large ovoid nucleus in which nucleoli were prominent. The cytoplasm was rich in tonofibrils, but mitochondria, Golgi material, and rough endoplasmic reticulum were sparse and tended to be located in the perinuclear region (Fig. 2a). The tonofibrils were condensed and formed linear bundles (Fig. 3a), particularly in relation to the desmosome attachments, but this was less noticeable in the region of the hemidesmosomes at the base of 

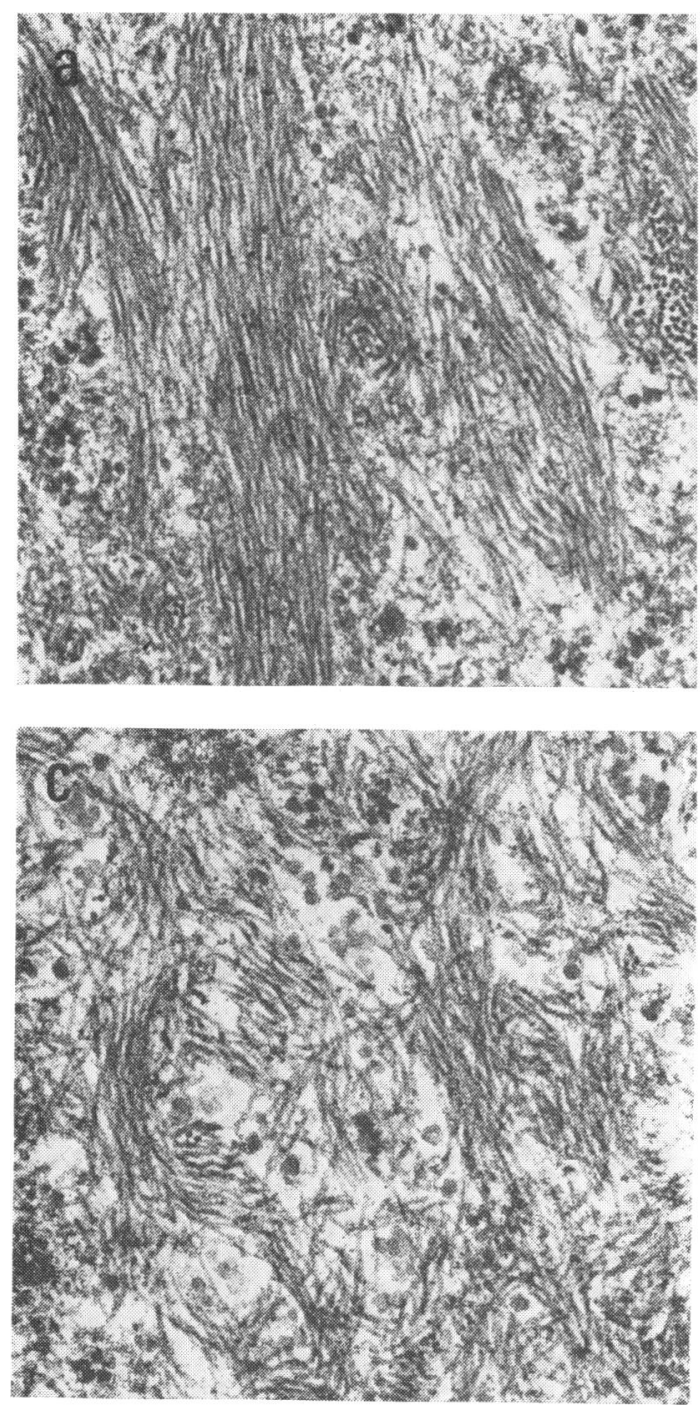

the cell. The cell membrane at the apex was undulating, and, although complex interdigitations were formed, the intercellular spaces were wide in this zone. The basement membrane formed a continuous electron-dense feltwork of fine filaments with some condensation in the region of the hemidesmosomes (Fig. 2a). Throughout the age range the morphological features of this layer were identical.

\section{Intermediate cells}

These consisted of polygonal cells with a less condensed cytoplasm than the basal layer. The organelle content was basically the same as that of the basal layer, except, that the mitochondria were larger, more electron-dense, and were dispersed evenly

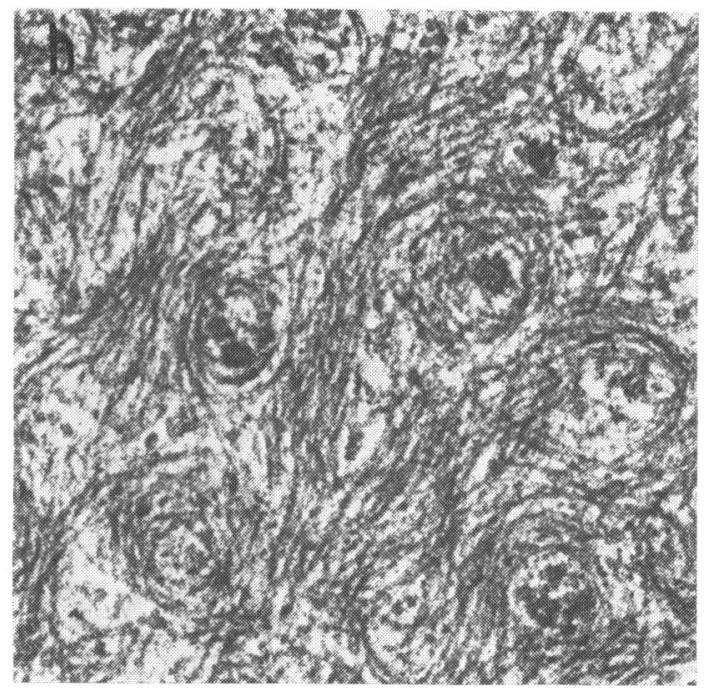

Fig. 3 To show the variable arrangement of the tonafilaments in (a) basal cells, (b) intermediate cells, and $(c)$ superficial cells $(\times 50000)$

throughout the cytoplasm (Fig. 2b). The tonofibrils were arranged as interwoven bundles which surrounded clumps of ribosomes or glycogen granules (Fig. 3b). The intercellular space was tortuous between the cytoplasmic infoldings in the biopsies from the 60 to 79 year old group, but in the older group the intercellular spaces were narrower and the cell membranes tended to be straighter and to be more parallel.

A noteworthy feature was the presence of a rodshaped cytoplasmic organelle which for convenience will be classified as a 'tubular body'. These structures were located near the cell membrane. They were dilated at each end and were membrane-bound, and the central core of the structure consisted of 


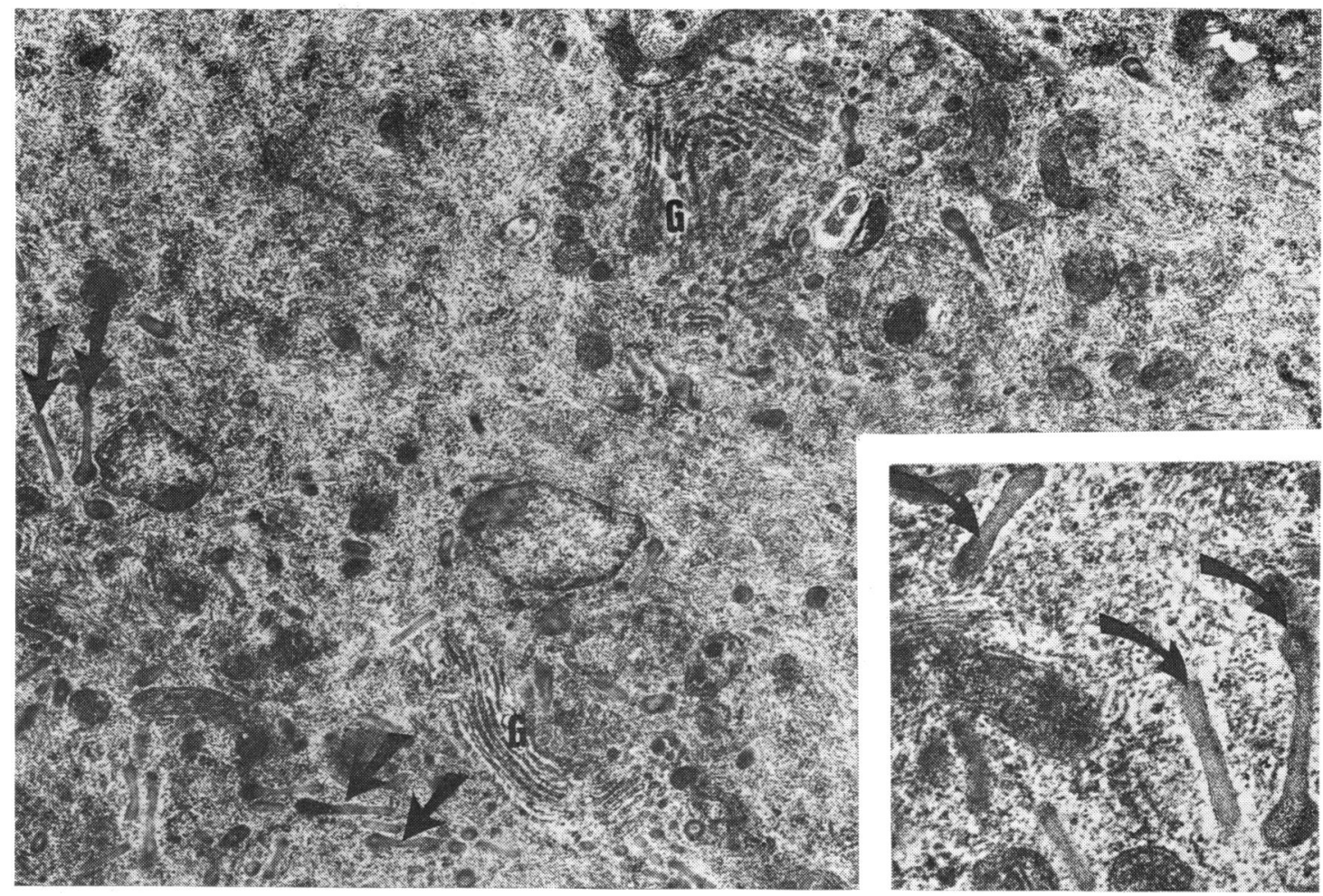

Fig. 4 Tubular bodies are plentiful (arrows) in the cytoplasm of the intermediate cells, in which Golgi apparatus (G) is also prominent $(\times 22000)$. The insert shows details of the tubular bodies

electron-dense granular material (Fig. 4). The incidence of lipid vacuoles, multivesicular bodies, and myelin figures was not apparently dependent on age.

\section{Superficial cells}

It was in the cells of this layer that variation with age was the most prominent feature. In the tissue from persons aged 50 to 79 the superficial cells were polygonal and their structural components were similar to those of the intermediate cell layers. In approximately one-third of the biopsies from persons older than 80 the shape of the superficial cells became flatter and more elongated. An associated feature was the narrowing of the intercellular spaces and a reduction in frequency, height, and width of the microplicae (Fig. 5b). The organelle content of these 'stratified' superficial cells did not alter significantly.

In some biopsies round electron-dense structures similar to those described by Takakusaki (1969) were found in the peripheral cytoplasm. When present they were found in all the epithelial cells other than the basal layer (Fig. 5).
Goblet cells

The morphology of the goblet cells in this group of biopsies was identical to that previously described (Freeman, 1962, 1964). The cells were located in the superficial and intermediate cell layers, and their shape depended on their stage of secretion. In the mature stage the cell cytoplasm literally assumed the shape of a 'goblet' with displacement of the nucleus to the base of the cell, and the central region of the cell was filled with secretory granules (Fig. 6). The secretory granules were generally ovoid in shape and were surrounded by a membrane. Their substance was formed from alternating lamellae of electron-dense granular material, but the size and shape of the granules depended to some extent on the stage of the secretory cycle. In the early stage the secretory granules were smaller and more circular than in the mature stage, in which they were compressed.

\section{Hyaline bodies}

These amorphous structures, which were observed in the superficial layers of the epithelium by light microscopy, were studied in all 4 specimens by the 
Fig. 5 To show the comparison between (a) the surface of a normal cuboidal superficial cell with normal microplicae and (b) the surface of a superficial elongated cell in which the microplicae are stunted and reduced in number. Electron-dense structures are shown by an arrow. (a) $\times 26000$; (b) $\times 15000$

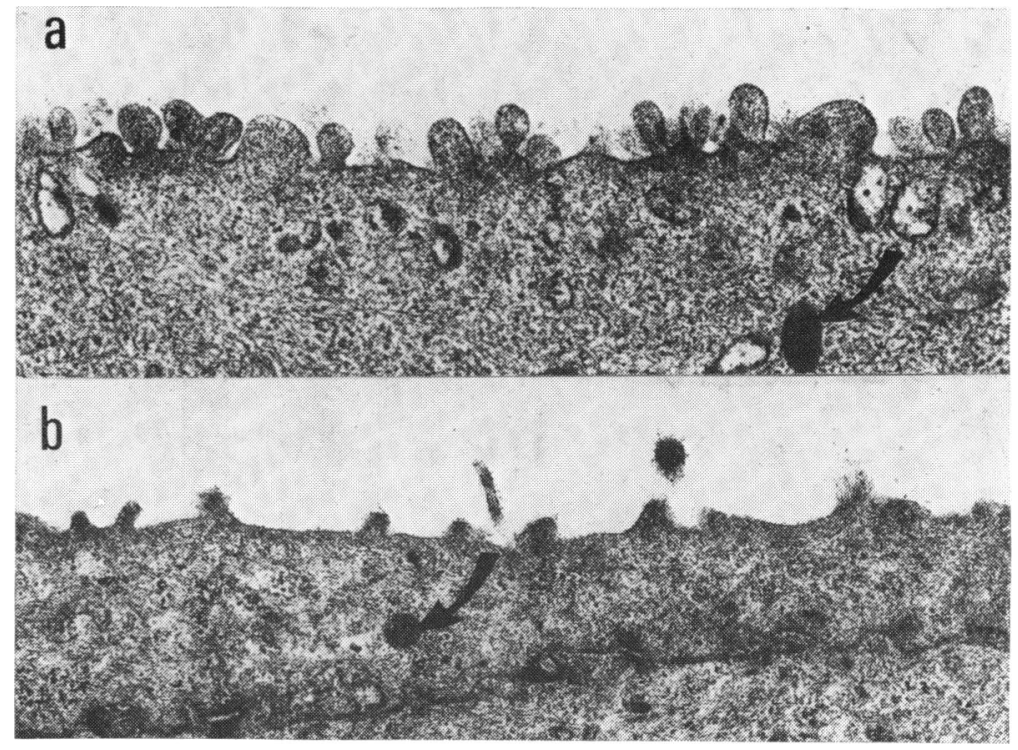

transmission electron microscope. These 'hyaline bodies' were 2 to 3 times the size of goblet cells and were constantly circular or oval in shape. They consisted of a central, or sometimes an eccentric, electron-dense granular mass which was surrounded by a lucent zone, and this contained smaller electrondense particles (Fig. 7). At the periphery of this electron-lucent zone there was an electron-dense rim which had an interrupted trilaminar membrane on its inner surface. The structure of this rim was found to consist of cytoplasmic tonofibrils, ribosomes, and degenerated cytoplasmic organelles. At the periphery of the central granular mass and in the lucent zone there were groups of parallel membrane-like structures interposed between granular material and small round membrane-bound circular structures of varying size. The complete 'hyaline body' was surrounded by a cell membrane bearing normal desmosome attachments.

\section{Discussion}

A previous study of tear secretion in geriatric inpatients aged over 80 indicated that $16 \%$ suffered from mild keratoconjunctivitis sicca (KCS). None of these patients had rheumatoid arthritis or proved connective tissue disease, which suggests that reduction in tear fluid was a phenomenon of increasing age (Whaley et al., 1972). The clinical criteria for defining KCS are imprecise, particularly with reference to the Schirmer's tear tests and the degree of staining with Rose Bengal dye.

It is the contention of one of us (J. W.) that the dry eye syndrome is underdiagnosed, and it is possible that more precise information, for example, could be obtained from a conjunctival biopsy.

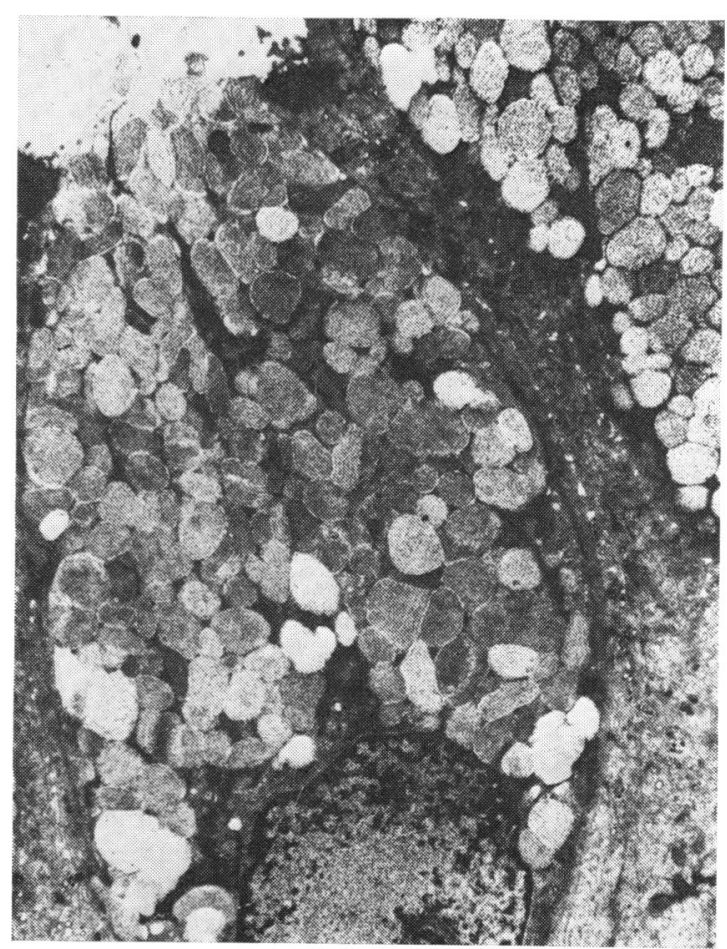

Fig. 6 A mature goblet cell filled with secretory granules $(\times 5000)$ 

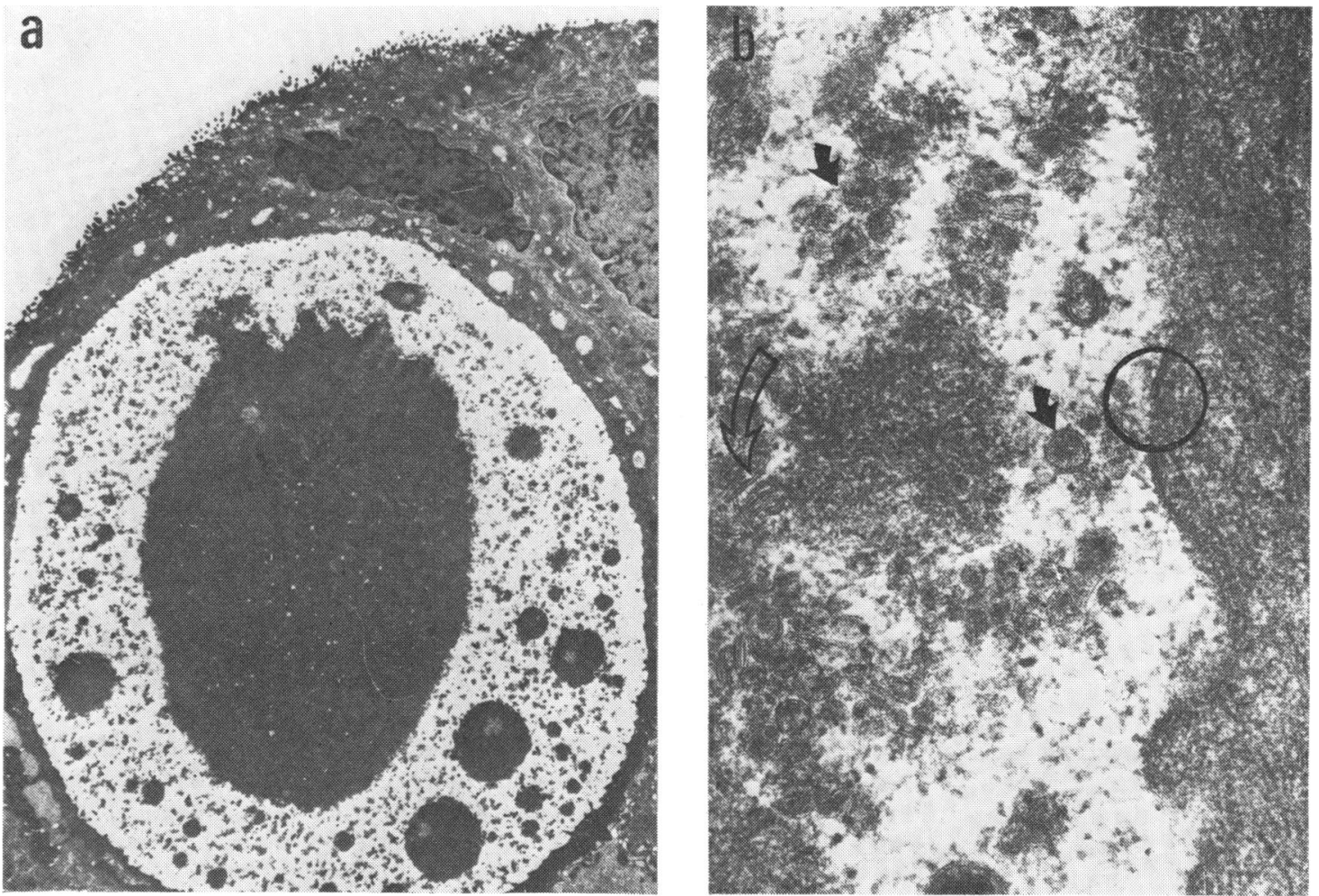

Fig. 7 A 'hyaline body' in the conjunctival epithelium. (a) is a low power to show the electron-dense core and the surrounding lucent zone $(\times 3800) ;(b)$ is a higher power to show the parallel membrane-like structures (open arrow) interposed between granular material and smaller membrane-bound circular structures (fine arrows). The electron-lucent zone is limited by electron-dense material bounded internally by a trilaminar membrane (circle) $(\times 90000)$

However, this presents difficulties because: (1) There is regional variation in conjunctival morphology, and (2) there does not appear to be any documentation of age change in the normal conjunctiva. Furthermore, only a few reports on the fine structure of the conjunctiva are available (Suzuki, 1956, 1957; Shibuya, 1958; Fujiyama, 1961), and these deal with relatively few specimens which were taken from the upper fornix. In the reports of Wanko et al. (1964) and Takakusaki (1969) on the perilimbal and palpebral conjunctiva respectively, only 6 and 4 normal conjunctival biopsies were studied, and this was insufficient to document age changes.

In the present investigation it was apparent from light and electron microscopy that significant morphological changes were rare before the age of 79 years. Segmental flattening of the epithelial cells was, however, seen in some $30 \%$ of biopsies from the group over 80 and much less frequently in the younger age groups. A constantly related feature in these patients was a lowered goblet cell count. It would appear that there was a common factor in this relationship and that there could have been a direct influence of the epithelial cells on the goblet cells. On the other hand both types of cells could have reacted to a change in their environment, as, for example, to reduced tear quantity or quality.

Alteration in the anterior surface of the elongated cells of the epithelium consisted of a reduction (size and number) of microplicae and in the incidence of the micropinocytotic vesicles. The changes in microplicae could be the result of attenuation of the cell membrane, the significant effect of which would be a disturbance in stability of the tear film. Furthermore, as micropinocytosis is thought to be a process by which macromolecules are transported into a cell, an instability of the tear film could be responsible for the lowered prevalence of micropinocytotic vesicles.

The epithelial cells did not show changes which could be associated with non-specific ageing degeneration. For example, lipofuscin granules, auıphagosomes, and myelin figures were not constant 
or significant features in the epithelial cells from the group aged over 79 .

In addition in the group aged 80 and over, if the trends are valid, the results suggest that there is a quantitative decline in the goblet cell population. The normal goblet cell population is approximately $10 / \mathrm{mm}$, the proportion depending on the site studied, the highest concentration being in the lower nasal bulbar conjunctiva (Kessing, 1966, 1968; Ralph, 1975). In this series of 49 patients the goblet cell count of 9 to $10(\mathrm{SD} \pm 4)$ confirms the above findings. However, in the group aged 80 years and above the count dropped significantly to $6 \pm 3$. It is important to note, however, that neither the light nor the transmission electron microscopic studies showed any significant changes in the goblet cell morphology in any of these groups. This observation does not exclude the possibility that the basic chemical constituents of goblet cell mucosubstances were altered in a significant manner, but this is an interesting possibility and a histochemical analysis of this material is in progress.

Kessing (1968) has described alterations in the goblet cell structure and content in up to $50 \%$ of his series of patients. His contention was that the goblet cells of older people contained a high proportion of neutral mucopolysaccharides, unlike the goblet cells of younger people, in which the mucopolysaccharides were acidic. In addition, he observed frequent occlusion of the goblet cells with retention of their contents, a phenomenon which was reported to increase with age. Thus, Kessing felt that $50 \%$ of the goblet cells in elderly patients were abnormal.

In the present series, although we have been unable to confirm Kessing's findings, we have demonstrated the presence of 'hyaline bodies' in $25 \%$ of persons aged 80 and over. These, like the goblet cells, were PAS-positive and were usually associated with a low goblet cell count, suggesting a relationship between these 'hyaline bodies' and the goblet cells. In addition, if this concept holds true, that is, if the 'hyaline bodies' are due to intracytoplasmic degeneration within the goblet cells, the small membrane-like structures and the circular bodies which were seen by the transmission electron microscopy could be representative of broken down secretory granules, and the size relationships of their trilaminar membranes favours this. But since no transitional forms between goblet cells and hyaline bodies were seen in the present study the possibility of these 'hyaline bodies' being a degenerative form of goblet cells is still speculative. It has to be admitted, however, that 'hyaline bodies' were observed in only 4 of the 16 specimens examined, and the technique of transmission electron micro- scopy allows the examination of only small samples of tissue.

A converse situation occurred with regard to the tubular bodies (Fig. 4), which were a common feature in the intermediate cell layer. Structures similar to these bodies are a well established feature of endothelial cells throughout the vascular system (Weibel and Palade, 1964; Matsuda and Sugiura, 1970), and they were considered to be derived from the Golgi apparatus. Their function is unknown, but there has been a suggestion that in the endothelium these structures are involved in coagulation.

This research was conducted under the auspices of the W. H. Ross Foundation (Scotland) for the Study of Prevention of Blindness. The authors wish to thank Mr R. A. Muirhead and Mr J. Ralston for their technical support and Mrs P. Bonnar for secretarial assistance.

\section{References}

Freeman, J. A. (1962). Fine structure of the goblet cell mucous secretory process. Anatomical Record, 144, 341-345.

Freeman, J. A. (1964). Goblet cell fine structure. Anatomical Record, 154, 121-147.

Fujiyama, H. (1961). Electron microscopic studies on the conjunctiva, sclera, cornea and lens crystalline. Acta Societatis Ophthalmologicae Japonicae, 65, 2101-2125.

Kessing, S. V. (1966). Investigations of the conjunctival mucin. Quantitative studies of the goblet cells of the conjunctiva. Acta Ophthalmologica, 44, 439-453.

Kessing, S. V. (1968). Mucous gland system of the conjunctiva. A quantitative normal anatomic study. Acta Ophthalmologica, Suppl. 95.

Matsuda, H., and Sugiura, S. (1970). Ultrastructure of 'tubular body' in the endothelial cells of ocular blood vessels. Investigative Ophthalmology, 12, 919-925.

Ralph, R. A. (1975). Conjunctival goblet cell density in the normal subjects and in dry eye syndrome. Investigative Ophthalmology, 14, 299-302.

Shibuya, Y. (1958). Electron microscopy by ultrathin specimens of normal human conjunctiva. Report I. Conjunctiva of the fornix. Acta Societatis Ophthalmologicae Japonicae, 62, 1204-1213.

Suzuki, A. (1956). Fine structure of normal human conjunctiva. Electron miscroscopy in ultrathin section. Acta Societatis Ophthalmologicae Japonicae, 60, 441-459.

Suzuki, A. (1957). Fine structure of normal human conjunctiva as revealed by electron microscopy in sections. Acta Societatis Ophthalmologicae Japonicae, 61, 2254-2258.

Takakusaki, I. (1969). Fine structure of the human palpebral conjunctiva with special reference to the pathological changes in vernal conjunctivitis. Achirum Histologicum Japonicum, 30, 247-282.

Wanko, T., Lloyd, B. J., and Mathews, J. (1964). The fine structure of human conjunctiva in perilimbal zone. Investigative Ophthalmology, 3, 285-301.

Weibel, E. R., and Palade, G. E. (1964). New cytoplasmic components in arterial endothelia. Journal of Cell Biology, 23, 101-112.

Whaley, K., Williamson, J., Wilson, T., McGavin, D. D. M., Hughes, G. R. V., Hughes, H., Schmulian, L. R., MacSween, R. N. M., and Buchanan, W. W. (1972). Sjögren's syndrome and autoimmunity in a geriatric population. Age and Aging, 1, 197-205.

Wolfe, G. (1967). Anatomy of the Eye and Orbit, 7th edn. Lewis: London. 